\title{
THE MANAGEMENT OF ACUTE ACROMIOCLAVICULAR DISLOCATION
}

\author{
A RANDOMISED PROSPECTIVE CONTROLLED TRIAL \\ GORDON C. BANNISTER, W. ANGUS WALLACE, P. G. STABLEFORTH, M. A. HUTSON
}

From Bristol Royal Infirmary and Queen's Medical Centre, Nottingham

\begin{abstract}
In a prospective study, 60 patients with acute acromioclavicular dislocation were randomly allocated to treatment with a broad arm sling or to reduction and fixation with a coracoclavicular screw. Of these 54 were followed for four years.

Conservatively-treated patients regained movement significantly more quickly and fully, returned to work and sport earlier and had fewer unsatisfactory results than those having early operation. For severe dislocations, with acromioclavicular displacement of $2 \mathrm{~cm}$ or more, early surgery produced better results. Conservative management is best for most acute dislocations, but younger patients with severe displacement may benefit from early reduction and stabilisation.
\end{abstract}

Since Cooper (1861) first operated for acromioclavicular dislocation in the pre-antiseptic era, there have been conflicting opinions about management. Operation is said to give superior results in manual workers (Horn 1954), sportsmen (Kennedy and Cameron 1954) and members of the armed services (Kato et al 1984), but comparable results have been reported after conservative management of these groups of patients (Urist 1946; Imatani, Hanlon and Cady 1975; Glick et al 1977).

We therefore designed a randomised prospective controlled trial including sufficient numbers to clarify the indications for operative and conservative management.

\section{MATERIAL AND METHODS}

From 1980 to 1983 , a total of 60 consecutive patients with acute acromioclavicular dislocation seen at the Royal Infirmary, Southmead and Frenchay Hospitals, Bristol (40), and the University Hospital, Nottingham (20), attended a special weekly clinic in their respective

G. C. Bannister MCh Orth, FRCS Ed Orth, FRCS, Consultant and Senior Lecturer in Orthopaedic Surgery

Southmead Hospital, Westbury on Trym, Bristol BS10 5NB, England.

W. A. Wallace FRCS Ed (Orth), Professor of Orthopaedic and Accident Surgery

Queen's Medical Centre, Nottingham NG7 2UH, England.

P. G. Stableforth, FRCS, Consultant Orthopaedic Surgeon, The Royal Infirmary, Marlborough Street, Bristol BS2 8HW, England.

M. A. Hutson, MA, MB, BCh, Orthopaedic Physician,

Park Row Clinic, 30 Park Row, Nottingham NG1 6GR, England.

Correspondence should be sent to Mr G. C. Bannister.

1989 British Editorial Society of Bone and Joint Surgery $0301-620 \mathrm{X} / 89 / 5146 \$ 2.00$

J Bone Joint Surg [ Br] 1989:71-B :848-50 cities. The patient's age, sex, occupation and manner of injury were recorded; standard and weight-bearing radiographs (Tossy, Mead and Sigmond 1963) were taken. Patients gave informed consent before entry to the trial. A random number was drawn and the patient allocated to operative or conservative management.

Surgery was performed under general anaesthesia within 10 days of injury. Through an anterior oblique incision the acromioclavicular joint was inspected and its meniscus removed. Any disruption of the anterior attachment of the deltoid was recorded and the joint was reduced and held with a temporary Kirschner wire. The clavicle was then fixed to the coracoid process with an AO cancellous or malleolar screw and washer, with overdrilling to facilitate insertion of the screw and to allow some independent rotation. The coracoclavicular ligaments were not reconstructed, but the origin of the deltoid was meticulously repaired. Suction drainage was used and the limb protected in a broad arm sling for two weeks, when the sutures were removed. The patient then started rehabilitation (Glick et al 1977), with increasing movement and weight training supervised by a physiotherapist. Screws were removed after six weeks.

Conservative management involved a two-week period of rest in a broad arm sling followed by the same programme of rehabilitation as the operated patients.

Follow-up review was after 6,12 and 16 weeks, and then at one and four years. Range of movement, power and pain were recorded on an objective scale (Table I) used in previous studies (Imatani et al 1975; Avikainen et al 1979). This functional scoring system demotes a result to 'fair' if there is slight pain and weakness, but does not take account of the appearance of the shoulder. 
Table I. The Imatani evaluation system for acromioclavicular dislocation

\begin{tabular}{lll}
\hline Distribution & & Score \\
\hline Pain & None & 40 \\
(40 points) & Slight, occasional & 25 \\
& Moderate, tolerable. limits activities & 10 \\
& Severe, constant, disabling & 5 \\
Function & Weakness (proportion of pre-injury) & 20 \\
(30 points) & Use of shoulder & 5 \\
& Change of occupation & 5 \\
Movement & Abduction & 10 \\
(30 points) & Flexion & 10 \\
& Adduction & 10 \\
Result & Excellent & 91 to 100 \\
& Good & 81 to 90 \\
& Fair & 61 to 80 \\
& Poor & $<61$ \\
\hline
\end{tabular}

Table II. Results of conservative treatment of 33 patients (percentage)

\begin{tabular}{llll}
\hline Review & Perfect & $\begin{array}{l}\text { Good or } \\
\text { excellent }\end{array}$ & Fair \\
\hline One year & 50 & 38 & 12 \\
4 years & 59 & 41 & \\
\hline
\end{tabular}

Table III. Results of operation in 27 patients (percentage)

\begin{tabular}{llll}
\hline Review & Perfect & $\begin{array}{l}\text { Good or } \\
\text { excellent }\end{array}$ & Fair \\
\hline One year & 50 & 27 & 23 \\
4 years & 60 & 24 & 16 \\
\hline
\end{tabular}

Table IV. Results in 12 patients with severe dislocation $(<2 \mathrm{~cm})$

\begin{tabular}{lll}
\hline Management & $\begin{array}{l}\text { Good or } \\
\text { excellent }\end{array}$ & Fair or poor \\
\hline Conservative & 1 & 4 \\
Surgical & 5 & 2 \\
\hline
\end{tabular}

\section{RESULTS}

Sixty patients (58 men and two women) entered the trial. Their mean age was 32.5 years. Two-thirds of the patients were manual workers and the remainder sedentary. Of the 60 dislocations, 37 were sustained during sporting activity, 17 in road traffic accidents and six at work. Thirty-three patients had conservative management and 27 had an operation. Two patients were lost to follow-up after one year, and six after four years (two had died).

Outcome. Manual workers treated conservatively returned to work after an average of four weeks and those managed surgically after 11 weeks. Conservativelytreated clerical workers returned to work in one week, those after operation in four weeks $(p<0.01)$. The mean time for return to sport was 11 weeks; seven weeks after closed treatment and 16 weeks after surgery $(\mathrm{p}<0.05)$.

After four months, $88 \%$ of the conservatively-treated cases had regained a full range of movement compared with $40 \%$ of the operated group. Some $90 \%$ of all patients had recovered full power.

After one year, $88 \%$ of conservative and $77 \%$ of operated patients had good or excellent results. In the conservative group (Table II), $50 \%$ were perfect, $38 \%$ good or excellent and $12 \%$ fair. Of the early surgery group (Table III) $50 \%$ were perfect, $27 \%$ were good or excellent and $23 \%$ were fair or poor. Two of these patients subsequently deteriorated.

After four years, $59 \%$ of the conservative group were perfect and the remainder good or excellent, whereas of the surgical patients $60 \%$ were perfect, $24 \%$ good or excellent and $16 \%$ remained fair.

In the 12 dislocations with acromioclavicular separation of $2 \mathrm{~cm}$ or more, operation gave more perfect functional results (Table IV). For all cases we found no difference in results in sportsmen, manual workers or policemen. Patients over $\mathbf{4 0}$ years of age fared slightly worse after surgical management.

Failures. Four patients in the conservatively-managed group eventually required operation; one for unacceptable shoulder weakness, two for painful subluxation and one for appearance.

In two surgically-treated patients, the screw cut out of the clavicle and in a third, the screw broke. Two other patients required re-operation for painful subluxation.

None of those patients who had secondary operations had an excellent result but after four years all but one were good.

Anatomy. In conservatively-managed shoulders, both acromioclavicular and coracoclavicular separations reduced by $5 \mathrm{~mm}$ over the first year. The operated cases were all initially fixed anatomically but reduction was lost in $35 \%$ when the coracoclavicular screw was removed. The mean reduction of acromioclavicular separation achieved by surgery was $12 \mathrm{~mm}$, that is $4 \mathrm{~mm}$ more correction than that from conservative management.

\section{DISCUSSION}

Our results agree with those of other prospective comparisons of conservative management with a wide variety of operations (Imatani et al 1975; Larsen, BjergNielsen and Christensen 1986). This suggests that closed treatment of acromioclavicular dislocation gives superior results to early operation.

Severe acromioclavicular dislocation involves rupture of the coracoclavicular ligaments and avulsion of the anterior fibres of the deltoid (Horn 1954). A surgical approach to the region involves more muscle detachment 
and an extension of partial lesions. This produces greater morbidity than conservative treatment for the milder dislocations; it may explain why only the most severe disruptions benefit from early surgery.

The anatomical gains of surgery are small; some loss of reduction follows all operations. This varies from $20 \%$ (Paavolainen et al 1983) to $40 \%$ (Kato et al 1984). Weitzman (1967) left coracoclavicular screws in situ for 12 weeks. Only $16 \%$ of his cases lost position, which suggests that fixation devices should be retained for more than six weeks since the injury takes longer to stabilise.
Our results indicate that in the average case the closed treatment of acute acromioclavicular dislocation is superior to early open reduction and coracoclavicular screw fixation. However, younger patients with severe displacement are more likely to achieve an excellent result if the injury is stabilised early.

No benefits in any form have been received or will be received from a commercial party related directly or indirectly to the subject of this article.

\section{REFERENCES}

Avikainen V, Ranki P, Turunen M, Lepistö P, Rokkanen P. Acromioclavicular complete dislocation: analysis of the operative results in 48 patients. Ann Chir Gynaecol 1979;68:117-20.

Cooper ES. New method of treating long standing dislocations of the scapulo-clavicular articulation. Am J Med Sci 1861;41: $389-92$.

Glick JM, Milburn LJ, Haggerty JF, Nishimoto D. Dislocated acromioclavicular joint: follow-up study of 35 unreduced acromioclavicular dislocations. Am J Sports Med 1977:5:264-70.

Horn JS. The traumatic anatomy and treatment of acute acromioclavicular dislocation. J Bone Joint Surg [Br] 1954;36-B: 194-201.

Imatani RJ, Hanlon JJ, Cady GW. Acute, complete acromioclavicular separation. J Bone Joint Surg [ Am] 1975;57-A :328-32.

Kato F, Hayashi H, Miyazaki T, et al. Treatment of acute complete dislocation of the acromioclavicular joint. In: Bateman JE, Welsh RP, eds. Surgery of the shoulder. Philadelphia, etc: BC Decker Inc. St. Louis, etc: CV Mosby Co, 1984:67-9.
Kennedy JC, Cameron H. Complete dislocation of the acromioclavicular joint. J Bone Joint Surg [ Br] 1954;36-B:202-8.

Larsen E, Bjerg-Nielsen A. Christensen P. Conservative or surgical treatment of acromioclavicular dislocation: a prospective, controlled, randomized study. J Bone Joint Surg [Am] 1986;68-A: $552-5$.

Paavolainen P, Björkenheim J-M, Paukku P, S1ätis P. Surgical treatment of acromioclavicular dislocation : a review of 39 patients. Injury 1983;14:415-20.

Tossy JD, Mead NC, Sigmond HM. Acromioclavicular separations: useful and practical classification for treatment. Clin Orthop 1963;28:111-9.

Urist MR. Complete dislocations of the acromioclavicular joint: the nature of the traumatic lesion and effective methods of treatment with an analysis of forty-one cases. J Bone Joint Surg 1946;28: 813-37.

Weitzman G. Treatment of acute acromioclavicular joint dislocation by a modified Bosworth method: report on twenty-four cases. J Bone Joint Surg [Am] 1967:49-A:1167-78. 